\title{
Dairy producer perceptions of the Farmers Assuring Responsible Management (FARM) Animal Care Program
}

\author{
K. A. Rink, ${ }^{1}$ P. Turk, ${ }^{2}$ S. L. Archibeque-Engle,${ }^{3}$ H. Wilmer, ${ }^{4}$ J. K. Ahola, ${ }^{1}$ J. C. Hadrich, ${ }^{5}$ and I. N. Roman-Muniz ${ }^{1 *}$ \\ ${ }^{1}$ Department of Animal Sciences, Colorado State University, Fort Collins 80523 \\ ${ }^{2}$ Western Data Analytics, Lakewood, CO 80228 \\ ${ }^{3}$ Office of the Vice President for Diversity, Colorado State University, Fort Collins 80523 \\ ${ }^{4}$ USDA Agricultural Research Service Rangeland Resources and Systems Research Unit, Fort Collins, CO 80523 \\ ${ }^{5}$ Department of Applied Economics, University of Minnesota, St. Paul 55108
}

\section{ABSTRACT}

Dairy farms producing $98 \%$ of the US milk supply participate in the Farmers Assuring Responsible Management (FARM) Animal Care Program. Producers who sell milk to cooperatives or processors participating in FARM must follow program standards. The objectives of this study were to assess producer perceptions about the knowledge, experience, and value of FARM and to determine whether perceptions differ based on demographics. A concurrent triangulation design was implemented through collecting quantitative and qualitative data using a 30-question survey instrument. Quantitative questions aimed to address project objectives, and qualitative data were provided through 1 open-ended survey question that asked participants what they thought the main goal of the FARM program was. Participants offered additional feedback through providing text in comment boxes, writing on the back of the survey, or writing a separate letter and returning it with their survey. Quantitative data were analyzed using principal components analysis and modeling, and qualitative data were analyzed through thematic analysis. Dairy producers from cooperatives or processors that participate in the FARM program were recruited via electronic and postal mail. A total of 487 respondents from 40 states completed the survey. Of the survey participants, $414(85.0 \%)$ answered the open-ended question and $190(39.0 \%)$ provided additional qualitative feedback. Thematic analysis revealed 5 main themes: distrust of program, producers on the defense, anger, efficiency, and nostalgia. Of respondents, $73.6 \%$ reported being knowledgeable about the FARM Animal Care Program. Greater level of formal education and larger herd size were associated with greater

Received April 25, 2019

Accepted August 14, 2019.

*Corresponding author: noa.roman-muniz@colostate.edu producer knowledge. More dairy producer input in the revisions of FARM was identified as a need by $83.3 \%$ of respondents. Although $89.3 \%$ of respondents reported positive experiences with evaluations and relationships with evaluators, $45.6 \%$ did not think that the program had value overall. Respondent age was positively associated with perceived value of FARM. Respondent age was also significant in determining the reasons why FARM was considered to be important. Results indicate that to increase buy-in and positive perceptions from producers, future versions of FARM should solicit producer input during the development of program standards, target specific producer demographics for program promotion, and address perceived communication deficits and program inequalities. Findings from this study can be used to inform future versions of the program.

Key words: animal care, dairy producer, Farmers Assuring Responsible Management, survey

\section{INTRODUCTION}

The US dairy industry contributes $\$ 33.5$ billion to the economy each year, which accounts for $9.0 \%$ of agricultural sales (USDA, 2014). The total numbers of dairy farms, producers, and cows are decreasing, whereas average milk production, producer age, and herd size are increasing (USDA, 2012). This is driven by economies of scale that allow cost of production to decrease as herd sizes increase over time (Wolf, 2003; Wilson, 2011). Although herd size and dairy welfare challenges are not consistently related (Robbins et al., 2016), the shift toward larger herds and consumers' physical and social distance from agriculture have influenced perceptions (Wachenheim and Rathge, 2000) and contributed to consumer concern about the quality of care given to animals in production agriculture (Kendall et al., 2006). Consumer distance from agriculture has increased at a steady rate; almost $90 \%$ of Americans are 2 to 3 generations removed from production agriculture, and a mere 
$1.3 \%$ of US employment comprises direct on-farm jobs (USDA ERS, 2018).

Over the last few decades, animal welfare has received increased attention from consumers, agriculturalists, activists, and researchers alike. There has been increased interest from the public in cattle welfare (Cardoso et al., 2016; Wolf et al., 2016) and care and housing of milk-producing cows (von Keyserlingk et al., 2009). Today, an increasing number of consumers are concerned with where their food comes from and how it is raised; they support regulating farm animal care and report being willing to pay more for food that is humanely raised (Ellis et al., 2009; Tonsor and Wolf, 2011; Grimshaw et al., 2014). American consumers have had an influence over many large retailers and processors with interests aimed toward food safety and quality, and more recently have had influence over legislation regarding farm animal care (Dimitri et al., 2005; USDA ERS, 2016).

The increased attention to welfare by consumers, driven in part by animal rights activism and undercover videos, has resulted in the formation of auditing programs in the United States to allow livestock industries to verify integrity of animal care practices on-farm (USDA, 2017). The National Milk Producers Federation (NMPF), the dairy industry's primary policy and lobbying organization, and Dairy Management Inc., the US dairy promotion and checkoff association, agreed in early 2008 that developing a comprehensive, rigorous animal care program would be the best way to provide customers and consumers the assurance that they sought regarding the humane treatment of dairy cows.

In 2009, the first version of the Farmers Assuring Responsible Management (FARM) Animal Care Program (https://nationaldairyfarm.com/) was developed by a small group consisting of academics specializing in animal health and well-being, veterinarians, dairy cooperative and processor staff, industry experts, and dairy farmers. This group, slightly short of 20 individuals and today known as the technical writing group (TWG), assisted in creating 3 core elements of the program: a continuous improvement process to promote adequate on-farm animal care based on best management practices (program standards), second-party evaluations conducted by a trained FARM evaluator once every 3 yr, and integrity verification through third-party evaluations. An aggregate random sample from all eligible farms is selected each year for third-party evaluations.

The first version of the program was voluntary, and the last 2 versions became a requirement for producers who belong to cooperatives and processors participating in the FARM program. Version 3.0 of the program became effective January 1, 2017. As of the completion of this study, 115 cooperatives and processors from across the United States were enrolled in the FARM Animal Care program. The program revision process takes place every third year. This is completed by the TWG, the animal health and well-being committee, and the NMPF board of directors. The process commences with the TWG using the expertise of committee members and published scientific literature to revise current program standards. The drafted standards are then reviewed by the animal health and well-being committee, which consists of dairy processor and cooperative staff, industry professionals, and dairy farmers. These standards are revised between the 2 groups and then sent to the NMPF board of directors, which is made up of dairy farmers, for final approval. Before completion of this study, producer input on program revisions and committee involvement on a nationwide scale had not been reported in peer-reviewed literature. One to 3 dairy producers may serve on the TWG at a given time and provide input during initial program design and revision; however, this may not be an adequate representation of the diverse groups of dairy producers who participate in the FARM program. Producer representation and involvement in revising program standards is integral for realistic standards and perceived fairness of the revision process and could result in greater program buy-in.

To obtain adequate representation of the diverse groups of dairy farms, we conducted a nationwide survey of dairy producers who participate in the program to (1) assess the level of knowledge regarding the FARM program, (2) determine preferred sources of information, (3) identify the preferred training format, (4) assess producer experiences with the program, (5) determine the level of producer trust, (6) determine whether there was a perceived need for greater producer input, and (7) assess perceived value of the program. This research aimed to determine dairy producer knowledge, attitudes, and perceptions about the FARM Animal Care Program and inform future versions of the program by considering producer perspectives, which could in turn lead to greater producer buy-in.

\section{MATERIALS AND METHODS}

\section{Participants and Setting}

There are 2.1 million farmers in the United States, 64,000 of whom are dairy producers (USDA, 2012). The number of dairy producers has been decreasing each year, and from 2007 to 2012 this number decreased by $4.3 \%$ (USDA, 2012). An estimated 37,309 dairy producers participate in the FARM Animal Care Program (FARM Animal Care Program, 2017). The targeted population of dairy producers for the survey consisted 
of farms enrolled in the FARM program. Selection criteria for survey participants included (1) being a primary dairy operator, (2) belonging to a cooperative or processor that participates in the FARM Animal Care Program, and (3) operating a grade A dairy.

\section{Survey Instrument and Experimental Design}

With assistance from Colorado State University faculty, dairy producers, cooperative staff, FARM evaluators, and FARM program staff, a 30-question survey instrument was developed. The survey consisted of 20 content-based questions focused on the aforementioned objectives and 10 demographic questions. The format of these questions included Likert scale, binary, open ended, and categorical. On Likert scale questions, participants were asked to select a number on a 1-to-5 scale, where $1=$ strongly disagree, $2=$ disagree, $3=$ neutral, $4=$ agree, and $5=$ strongly agree. The first 19 of the content-based questions were quantitative, and the last question was open ended. If desired, producers could provide additional qualitative feedback through providing text in comment boxes, writing on the back of the survey, or writing a separate letter and returning it with their survey.

The project was designed as a concurrent triangulation mixed method. This method consisted of collecting qualitative and quantitative data concurrently through a survey instrument. Data were analyzed separately and were then combined to analyze comparatively to generate study findings. Quantitative findings were paired with qualitative with the rationale that combining qualitative and quantitative approaches provides a more complete answer to the study's research questions (Creswell and Plano Clark, 2011). Concurrent triangulation design is used to confirm, cross-validate, or corroborate findings (Creswell and Plano Clark, 2011). It is often used to overcome a weakness in one method using the strengths of another method. Further exploring quantitative data through collection of open-ended qualitative data can also help create a narrative.

\section{Data Collection and Recruitment}

The Institutional Review Board for Colorado State University reviewed and approved the survey and project methodology as exempt (protocol ID: 17-7113H). Upon project approval, the survey was disseminated in May 2017 in 2 recruitment phases.

Phase 1 of recruitment consisted of sending an email to all dairy cooperatives and processors that participate in the FARM program and met participation criteria. The email asked the dairy cooperatives and processors if they would like to participate in the survey. Completely randomized samples were drawn from the 42 cooperatives and processors that volunteered to participate. Samples were stratified by cooperatives and processors and were calculated based on the minimum sample size needed for a representative draw of the population $(\mathrm{n}=$ 379). A minimum threshold of 10 surveys were sent per cooperative and processor. A total of 1,549 surveys were sent via postal mail to producers who met participation criteria; this total was calculated using estimated response rate, minimum threshold per cooperative and processor, and minimum sample size needed for a statistically significant representation of the population. Surveys were sent using a modified Dillman method (Dillman et al., 2009), which consisted of a presurvey postcard, survey, and follow-up postcard. Each was sent at 2-wk intervals. Surveys were sent in envelopes that additionally contained a signed cover letter and a return-addressed envelope with postage included.

To maintain participant confidentiality, each survey was labeled with a unique code that corresponded to a name and address. The list of producer names and addresses was used to determine who to send follow-up postcards to and was not referenced after final survey distribution. The survey and follow-up postcard had a link to the survey online. In a previous Kentucky dairy producer survey, $62.0 \%$ of participants did not think the internet was an effective information delivery method (Russell and Bewley, 2013); however, we provided this survey in an online format to target producers who were frequent users of the internet and who would find an online format convenient.

Completion of the survey was voluntary and confidential, with no incentive for participation. This phase of recruitment gleaned 286 surveys (18.5\% response rate). In similar studies, the response rate ranged from 14.5 to $28.7 \%$ (Heguy et al., 2016; Wolf et al., 2016; Voelz et al., 2017).

To recruit more participants to reach the minimum sample needed $(\mathrm{n}=379)$ and to gather a better geographic representation of different states, a second phase of recruitment was completed. In this phase, survey invitations were extended to all producers associated with collaborating dairy cooperatives and processors via an email blast. This strategy, in conjunction with advertisement in a lay press dairy producer magazine and producers sharing information with their colleagues, allowed us to reach the minimum sample size. Phase 2 of recruitment gleaned 325 surveys. To reduce the risk of a producer participating more than once, each survey was mailed with a unique identifier code and only 1 electronic response per device was allowed through the online data collection software. One limitation of this recruitment phase was that by providing the survey in an online format only, producers who 
Table 1. Distribution of states by region based on Farmers Assuring Responsible Management (FARM) Animal Care Program enrollees

\begin{tabular}{ll}
\hline Region & States included $^{1}$ \\
\hline Midwest & $\begin{array}{l}\text { Iowa, Illinois, Indiana, Michigan, Missouri, Nebraska, Ohio, South Dakota } \\
\text { Northeast }\end{array}$ \\
Connecticut, Delaware, Maine, Massachusetts, New Hampshire, New Jersey, New York, Pennsylvania, Rhode Island, \\
Southeast & Alabanta, Arkansas, Florida, Georgia, Kentucky, Louisiana, Maryland, Mississippi, North Carolina, South Carolina, \\
& Tennessee, Virginia, West Virginia \\
Southwest & Arizona, Colorado, Kansas, New Mexico, Oklahoma, Texas \\
Upper Midwest & Minnesota, North Dakota, Wisconsin \\
West & California, Idaho, Montana, Nevada, Oregon, Utah, Washington, Wyoming \\
\hline
\end{tabular}

${ }^{1}$ Hawaii and Alaska are not included.

did not have access to the internet or email could not access the survey and participate.

\section{Data Analysis}

Quantitative data were analyzed using $\mathrm{R}$ statistical software (R Core Team, 2018). Surveys were categorized by region; Table 1 lists the states included in each region. Region was determined by FARM program enrollment per state; this ensured that each region had an evenly distributed number of program enrollees. Summary statistics were calculated for Likert scale data with the following numerical values assigned to each response: $1=$ strongly disagree, $2=$ disagree, $3=$ neutral, $4=$ agree, and $5=$ strongly agree.

Principal components analysis (PCA) was used to find linear combinations of a given set of questions to adequately describe most of the variation in the answers. A PCA was used for dimension reduction because some of the questions were moderately to highly correlated. Each PCA contained a group of correlated questions pertaining to perception of knowledge, experiences, and value.

General and generalized linear models were used to determine the relationships between PCA and the different demographic variables. Post hoc analysis (e.g., Tukey's multiple comparison procedure) was used when appropriate to determine how perceptions differed based on demographics. Family-wise error rate $(\alpha)$ was set at 0.05 for all tests with the exception of $F$-tests from the model, where 0.10 was used to determine important variables.

Qualitative data analysis was driven by the following question: "What are the overarching perceptions dairy producers have of the FARM Animal Care Program?" Data were analyzed as 2 separate data sets: open-ended data and additional feedback data. The open-ended question asked participants what they believed the main goal of the FARM Animal Care Program was. To systematically explore the complexity of these data sets, thematic analysis was used. Thematic analysis consists of the researcher searching through data for themes and patterns (Glesne, 2010). Themes were created by first developing a set of codes. Codes were inductively interpreted from data by the primary researcher. A final set of codes was developed and described in a code key for each data set. Code overlap occurred between data sets, and themes emerged from the coding process.

After the primary researcher completed coding, the code keys were distributed to members of the research team with training and expertise in qualitative analysis. Each researcher reviewed two-thirds of each data set. This ensured that every one-third of the data sets was coded by at least 2 researchers. Percentage agreement of codes was calculated as $79.6 \%$. Based on coding, 5 main themes emerged: distrust of program, producers on the defense, nostalgia, efficiency, and anger.

\section{Trustworthiness}

Creswell (1998) described 8 procedures that can be used to enhance trustworthiness in qualitative research: prolonged engagement and observation, triangulation, peer review and debriefing, negative case analysis, stating researcher bias and positionality, member checking, rich description and audit trails, and external audits. In this study, 4 of the 8 procedures were used: triangulation, debriefing, clarification of researcher bias (positionality), and audit trails.

Triangulation of researchers analyzing data was used to cross-validate findings and crystalize codes and themes used during thematic analysis. The involvement of researchers with different identity lenses enhances the credibility of this procedure, with 2 identifying as insiders in the dairy industry and 2 identifying as outsiders (Dwyer and Buckle, 2009). Interrater reliability (percentage agreement) was calculated to contribute to this, and triangulation between data analyses was used. Quantitative and qualitative data sets were analyzed separately and then used to analyze findings holistically. Results are presented in a manner that reflects the amalgamation of quantitative and qualitative 
analyses. Debriefing was used among the research team throughout data collection and analysis. Audit trails were created during the project through the use of memos, a research journal, and emails.

\section{RESULTS AND DISCUSSION}

A total of 611 surveys were returned via mail $(\mathrm{n}=$ $199)$ or online $(\mathrm{n}=412)$. Thirty were omitted because participants were not the primary operators of the dairy farms, and an additional 94 were omitted for being incomplete (i.e., only demographic questions were completed and content-based questions were not answered). This left 487 surveys for subsequent analyses: 199 were collected via hard copy and 288 were collected online; and 189 were completed during phase 1 of recruitment and 298 were completed during phase 2 . Of 487 survey participants, $414(85.0 \%)$ answered the open-ended question and 190 (39.0\%) provided additional qualitative feedback.

\section{Demographics}

Dairy producers in this study represented 40 states. The number of farms enrolled in the FARM program included in the NMPF database was compared with the number of survey participants by state. Results indicated that the survey sample by state was an adequate representation of the population; states with greater numbers of farms enrolled in the FARM program (e.g., Minnesota, Wisconsin, Pennsylvania) had more survey participants, and states with fewer farms enrolled in the FARM program (e.g., Washington, Kansas, North Dakota) had fewer survey participants. We received no surveys from Utah, Wyoming, Montana, Nevada, Oklahoma, Arkansas, Alabama, South Carolina, or Rhode Island. Hawaii and Alaska have no dairy producers who participate in the FARM program. Participating dairy producers represented 57 cooperatives and processors from across the nation. The targeted population of dairy producers for this survey was producers who are enrolled in the FARM program.

Sex, age, and herd size were divided into brackets based on USDA-defined bracket categories and were compared with USDA-reported statistics (Table 2). Eighty-three percent of survey participants were male and $16.8 \%$ were female. Respondent sex demographics were congruent with those reported by USDA (2012), in which $95.0 \%$ of dairy producers were male and $5.0 \%$ were female.

A total of $41.9 \%$ of participants were younger than $45 \mathrm{yr}$ of age, $50.9 \%$ were between 45 and $64 \mathrm{yr}$ of age, and $7.2 \%$ were $\geq 65$ yr of age $(\mathrm{n}=477)$. Comparatively, the census reported $28.0 \%$ of dairy producers being $<45 \mathrm{yr}, 57.0 \%$ being between 45 and $64 \mathrm{yr}$, and $15.0 \%$ being $\geq 65$ yr (USDA, 2012). Compared with USDA (2012) data, survey respondents with operations milking between 1 and 29 cows were underrepresented (4.8 vs. $32.4 \%$ ), whereas respondents milking more than 500 cows were overrepresented (23.4 vs. $5.6 \%$ ).

Following the predefined USDA income bracket categories, income was divided into 6 brackets (USDA, 2012): $36.6 \%$ of participants reported earning less than $\$ 50,000,27.5 \%$ earned $\$ 50,000$ to $\$ 100,000,13.4 \%$ earned $\$ 100,000$ to $\$ 250,000,7.0 \%$ earned $\$ 250,000$ to $\$ 500,000,5.7 \%$ earned $\$ 500,000$ to $\$ 1,000,000$, and $9.7 \%$ earned greater than $\$ 1,000,000(\mathrm{n}=454)$. The highest level of formal education attained was reported among participants in 6 brackets: elementary or primary school $(7.8 \%)$, middle school $(8.7 \%)$, high school (32.4\%), technical or trade school $(21.2 \%)$, bachelor's degree $(24.2 \%)$, and postgraduate degree (5.5\%; total $\mathrm{n}=472)$.

\section{Qualitative Themes}

Thematic analysis revealed that dairy producers perceived the FARM Animal Care Program from 5 main themes that emerged from the codes (listed most to least frequent): distrust of program, producers on the defense, anger, efficiency, and nostalgia. For a description of each theme, see Table 3. Data from an individual respondent could have been assigned more than 1 theme and a single phrase could have been assigned

Table 2. Comparison of demographic information from the sample of survey respondents and from the USDA (2012) US Census of Agriculture

\begin{tabular}{lccc}
\hline & \multicolumn{2}{c}{ Survey } & \\
\cline { 2 - 3 } Demographic & $\mathrm{n}^{1}$ & $\%$ & USDA $(2012), \%$ \\
\hline Sex & 482 & & \\
Male & & 83.2 & 95.0 \\
Female & 477 & 16.8 & 5.0 \\
Age, yr & & 41.9 & \\
$\quad<45$ & & 50.9 & 28.0 \\
$45-64$ & & 7.2 & 57.0 \\
$\geq 65$ & 479 & & 15.0 \\
Lactating cows, no. & & 4.8 & 32.4 \\
$1-29$ & & 10.2 & 16.7 \\
$30-49$ & & 28.2 & 25.0 \\
$50-99$ & & 13.4 & 13.6 \\
100-199 & & 8.4 & 6.6 \\
$200-499$ & & 7.1 & 2.7 \\
$500-999$ & & 7.9 & 1.6 \\
$1,000-1,999$ & & & 1.3 \\
$2,000+$ & & & \\
\hline
\end{tabular}

${ }^{1}$ Total number of survey participants who answered the demographic question. 
Table 3. Definitions of themes identified through thematic analysis of producer survey responses in qualitative data

\begin{tabular}{ll}
\hline Theme & Definition \\
\hline Anger & $\begin{array}{l}\text { Quotes or phrases that express disappointment, frustration, and anger with the program, implementation, } \\
\text { standards, or governing bodies }\end{array}$ \\
Quotes or phrases that question the intentions of the program, express distrust of the program, or question the \\
competence and trustworthiness of governing bodies \\
Quotes or phrases that mention increased costs associated with implementing the program on their farms, no \\
Efficiency \\
$\begin{array}{l}\text { perceived benefits caused by the program, or a need for compensation for program participation } \\
\text { Nostalgia }\end{array}$ \\
$\begin{array}{l}\text { Qull family stories, express pride, or reminisce about dairying } \\
\text { Producers on the defense } \\
\text { Quotes or phrases that express defensiveness, describe justification of practices, or express lack of input in } \\
\text { program revision and implementation }\end{array}$ \\
\hline
\end{tabular}

more than 1 theme due to codes overlapping among the themes.

\section{Knowledge, Preferred Training Format, and Sources of Information}

The PCA was completed using 5 questions that assessed the producers' perceived knowledge of the FARM Animal Care Program. After completing the analysis, the first identified principal component for knowledge (PCK) accounted for $60.3 \%$ of all the variation in the data. The larger the value of PCK, the greater the participant's knowledge of the FARM program. To compare the effect of PCK on sex, age, herd size, level of formal education, and region, F-tests were completed. There was a significant effect of PCK on level of formal education and herd size $(P=0.0044$ and $P=0.0411$, respectively). A greater level of formal education and a larger herd size generated a greater PCK value; producers with more cows or more years of formal education reported being more knowledgeable about the FARM program.

There were significant differences between geographical regions $(P=0.0202)$. Tukey's procedure revealed that participants in the Northeast region were different from those in the Midwest region $(P=0.0298)$, with those in the Northeast region reporting being more knowledgeable about the FARM program. Additionally, respondents in the Northeast region were more knowledgeable $(P=0.07)$ about the program than those in the Southeast region.

For the purposes of statistical analysis, the average participant was defined as someone who was of mean age $(47 \mathrm{yr})$ and mean level of formal education (1 yr of post-high school education) and had a mean herd size (170-175 cows), averaged over sex and region. The overall mean PCK score for the average survey participant was estimated as 0.0219 (95\% CI: -0.1524-0.1962). Because the confidence interval is strictly greater than the PCK score corresponding to neutral answers on all 6 questions ( $\mathrm{PCK}=-0.6773$ ), the average participant felt knowledgeable regarding the FARM program. Conversely, $8.5 \%$ did not think they were knowledgeable and $17.9 \%$ felt neutral.

Of 456 respondents, $41.0 \%$ indicated that they would attend a training session on the FARM program if one was available. When asked to select their preferred training format, participants indicated that their preferred method would be a packet of materials delivered to their farm $(28.3 \%)$. Other formats that participants preferred included on-farm training $(25.7 \%)$, a regional workshop (22.8\%), a national conference (12.0\%), and, last, an online training or webinar (11.3\%). Delivering a packet of materials to the farm is low cost and low input compared with hosting a meeting or workshop or delivering individual on-farm trainings. For many producers, time commitments and limited ability to leave the farm could be a barrier to attending other training types. For participants, the least preferred method of training was online. A previous Kentucky-based dairy producer survey yielded similar results, with more than half of participants reporting that the internet was not an effective information delivery method (Russell and Bewley, 2013).

Participants identified program communications as an area for improvement. One producer commented, "Please let us know what you [the FARM program] do and before making decisions about farming and talk with ALL farmers big and small." Another said, "I believe this is a good program I also believe it needs more communication between farmers and processors . . .."

Some agreed that the FARM program needed improved communications and suggested that NMPF should oversee the dissemination of information: "We need more info on the program and any changes, proposed or otherwise. We get very little info from our processor, and if NMPF is who created this program, they should be responsible for sharing that info with us." However, this was contradictory to whom some participants indicated should be responsible for informing stakeholders about the FARM program (Table 4). Cooperatives and processors were the top choice when 
Table 4. Groups that should be used to inform dairy stakeholders in the Farmers Assuring Responsible Management (FARM) Animal Care Program based on survey responses from members of dairy cooperatives participating in FARM

\begin{tabular}{lcc}
\hline Response & $\begin{array}{c}\text { Participants, } \\
\text { no. }\end{array}$ & $\begin{array}{c}\text { Total, } \\
\%\end{array}$ \\
\hline Cooperatives and processors & 167 & 39.7 \\
Dairy producers & 52 & 12.4 \\
FARM program evaluators and staff & 63 & 15.0 \\
Promotional groups and producer & 95 & 22.6 \\
$\quad$ associations & 25 & 5.9 \\
University extension & 19 & 4.4 \\
Veterinarians & 421 & 100.0 \\
Total & & \\
\hline
\end{tabular}

participants were asked who should be responsible for informing stakeholders about FARM (39.7\%). This was followed by promotional groups and producer associations $(22.6 \%)$ and FARM program staff (15.0\%). These findings indicate an opportunity for cooperatives and processors to communicate the FARM program to their dairy farmers. This information should be centralized for uniformity with FARM program staff, giving individual cooperatives and processors the ability to choose the platform for communicating program changes and standards.

\section{Internal and External Experiences}

A series of 6 questions were asked to understand participants' perceptions regarding their experiences with the FARM Animal Care Program. More than half of participants reported having a good working relationship with their FARM evaluator (59.5\%) and thought that a pre-evaluation meeting with their evaluator helped them understand what was going to happen during their evaluation (50.1\%). Almost two-thirds (65.1\%) of participants indicated that their FARM evaluator was qualified to do FARM evaluations, and $70.4 \%$ of participants thought that their past evaluations were handled correctly. Relationships with FARM evaluators and evaluations were perceived positively by the majority of participants.

When participants were asked whether they thought dairy producers should have more opportunities for input in the design and revision of the FARM program, $83.8 \%$ agreed that they should. More than one-third (37.1\%) of participants thought that third-party evaluations should not be used. Participants did not view experiences associated with the FARM program and TWG as favorably as experiences with evaluators.

A PCA was completed on questions related to perceived experience. The first principal component, internal experience (PCI), captured participant experi- ences with their evaluators and evaluations. The larger the value of PCI, the more positive the participant's internal experience with the FARM program. The second principal component, external experience (PCE), comprised questions involving the TWG and the programmatic elements of the FARM program. The larger the value of $\mathrm{PCE}$, the more positive the participant's external experience with the FARM program.

A general linear model was fit to examine the effect of PCI on demographics in sex, age, herd size, level of formal education, region, and whether the participant had a FARM evaluation in the past. There was a significant effect of PCI on whether the participant had a FARM evaluation in the past $(P=0.0009)$. Participants who reported having had an evaluation had a significantly more favorable internal experience with the FARM program.

The mean PCI score for the average participant was estimated to be -0.1629 (95\% CI: $-0.3746-0.0488$ ). Because the confidence interval is strictly greater than the PCI score corresponding to neutral answers on all 6 questions ( $\mathrm{PCI}=-1.0470)$, the average participant had a favorable internal experience with the FARM program, and participants perceived their experiences with evaluations and their evaluators positively. According to participants, FARM evaluators are doing a good job fostering relationships with producers and are handling FARM evaluations correctly. Of the many participants who reported this, one said, "We had an evaluator from our co-op come out and do an evaluation, they did a great job."

A general linear model was also fit to examine the effect of PCE on demographics in sex, age, herd size, level of formal education, region, and whether the participant had a FARM evaluation in the past. Results indicated that PCE had a significant effect on sex $(P=$ 0.0388). Both males and females reported an unfavorable external experience with the FARM program, with males having a more negative experience.

The mean PCE score for the average participant was estimated to be 0.2908 (95\% CI: $0.0772-0.5044)$. The confidence interval is strictly less than the PCE score corresponding to neutral answers on all 6 questions $(\mathrm{PCE}=1.2796)$, meaning that the average participant reported having an unfavorable external experience with the FARM program. This was captured in the qualitative data as well. Participants expressed anger and distrust with the FARM program. For example, one producer said, "When this program first started we [the farmers] were assured that this program would be used only as a guide to on farm management. That was a lie, now this program is being used to regulate and force farms to use practices that may hurt their bottom 
line. Not happy with certain aspects of the program." Another expressed that their peer group has met to discuss their frustration and anger with the program: "It's embarrassing [the program]. I speak for many producers. We've held meetings to discuss how awful this program is and our options to deal with it."

It is possible that producers feel at a loss with their distrust in the program. Another producer expressed anger by stating, "I could not think of a more offensive and condescending program than the FARM program and if it was not mandatory I would have no part in it." Anger was a recurring theme, much like distrust for producers who were on the defense. One producer said, "The FARM program is a joke..." and "You can fix this program by scrapping it." These participants were 3 of many who expressed anger with the FARM program. Some producers indicated feeling attacked, angry, and defensive because of consumer and activist demands. One producer highlighted this with a simile: "We [producers] feel like kindergarteners. I don't ask you to explain how you raise your kids or do your job, I trust you are doing it right. I would appreciate the same courtesy." Many of the angry qualitative responses from the survey highlighted participants' distrust in the FARM program and negative external experiences. One code identified within these sets of responses was a concern for a lack of producer input in the program.

Assistance from producers who view the FARM program favorably could be solicited for program promotion and to assist in building rapport among the dairy community. Evaluators could also help to build trust if equipped with clear messaging points to share with producers.

\section{Trust and Producer Input}

When participants were asked whether they thought dairy producers should have more opportunities for input in the design and revision of the FARM Animal Care program, $83.8 \%$ agreed that they should. More producer input was identified by many participants. One producer said, "FARM is no longer what is best for the animal but what is best for political correctness." Another commented, "When will the FARM Program start standing up for the farmer (and their animals)?"

Not only were these producers dissatisfied with the program, but they also suggested that producers need more representation and opportunities for input in the design and revision of the program. One producer claimed, "The tail docking issue was handled with zero input from actual producers. There is an established procedure for comments and hearings on changes to the program which were circumnavigated."
Less than half of participants $(41.5 \%)$ indicated that they trusted the TWG will make informed decisions when updating the FARM program, and many producers stated frustration with this through qualitative data. For example, one producer said, "We have never been able to vote for people on this FARM board, or committee [TWG]."

Many participants attributed program distrust to the idea that "outsiders" were running the FARM program and controlling how they manage their operations. Producers described outsiders as different stakeholder groups; some stated that they were "office dwellers," others referred to individuals engaged in program governance, and some referred to the TWG specifically. One producer said, "Maybe everyone making the rules should actually milk cows for a year before telling us what to do." Another said, "The committee [TWG] did a very poor job at looking at the whole picture when creating the program." Many of the producers who mentioned outsiders such as the TWG or nondairy individuals running the FARM program also mentioned a loss of trust in the program because of this.

Additional representation on the TWG or development of a producer committee could mitigate perceived program inequalities and assist with increasing producer input. By being engaged in the planning and revision process, producers could provide invaluable insight into future program versions. Furthermore, communications initiated by cooperatives and processors should include more detailed information about who serves on the TWG because many of the individuals in the group have strong dairy backgrounds.

\section{Perceived Value and Inequalities}

Four questions were asked to better understand participants' perceptions regarding value of the FARM Animal Care Program. Almost half of participants $(47.4 \%)$ did not think the FARM program was beneficial to their cows' health and well-being, and $62.3 \%$ did not think the program improved their farm's profitability. When asked if they thought the FARM program addressed consumer hot topics in the dairy industry, $46.4 \%$ of participants indicated that it did, meaning that this was the highest regarded value statement in this set of questions in respect to mean Likert score.

A PCA was completed on questions related to perceived value $(\mathbf{P C V})$. The larger the PCV, the more value the participant believed the FARM program had. A general linear model was fit to examine the effect of PCV on the demographics of sex, age, herd size, level of formal education, and region. There was a significant effect of PCV on sex, age, herd size, and region 
$(P=0.0179,0.0333,0.0240$, and 0.0361 , respectively $)$. Females had a neutral impression of the value of the FARM program, and males had an unfavorable one. The older the participant and the larger herd size the participant reported, the more value the participant assigned to the FARM program.

Additionally, age was significant in determining how participants answered why the FARM program was important to them $(P=0.0073)$. The older the participant, the more likely they were to indicate that the FARM program was important to them because it improved animal health and well-being and it unified the industry on animal welfare instead of indicating that the program was not important to them.

Perceived value had a significant effect on the reasons indicated for assigning value to the FARM program $(P$ $<0.0001)$. As the PCV increased, participants were more likely to say that the FARM program was important because it improved animal health and welfare. Participants with a lower PCV were most likely to say that the program was not important to them.

Tukey's procedure revealed tendencies between PCV and region. The confidence intervals from the Northeast, Southwest, and West regions contained the PCV score corresponding to neutral answers on all 4 questions $(\mathrm{PCV}=0.4158)$, suggesting that participants in these regions perceived the value of the program neutrally. Comparatively, the confidence intervals from the Midwest, Southeast, and Upper Midwest regions were strictly less than this PCV score. This suggest that participants in these regions had an unfavorable opinion of the value of the FARM program.

The mean PCV score for the average participant was estimated to be 0.1808 (95\% CI: 0.0038-0.3578). The confidence interval is strictly less than the PCV score corresponding to neutral answers on all 6 questions $(\mathrm{PCV}=0.4158)$, meaning that the average participant reported thinking the FARM program was not valuable. Overall, $45.6 \%$ of participants did not think the FARM program was valuable to their operation.

Many producers indicated they did not see value due to inequalities in the program. Although the FARM Animal Care Program is intended to be facility neutral, perceived program inequalities were expressed through the lens of smaller and organic dairy farms. One producer highlighted perceived inequalities by stating, "I feel the FARM program is forcing certain management techniques on us that are not beneficial to every operation." An organic producer stated, "This program is redundant and foolish on organic family farms." This point is further emphasized by another producer who stated, "We far exceed the requirements of FARM with our organic certification, which FARM ignores." To these producers, the FARM program is redundant and burdensome because it doesn't necessarily fit the needs of all producers equally.

Participants also expressed concern with program standards pertaining to large and small operations. For example, one producers said, "I personally think as a small family farm I do not think FARM is even applicable to my farm. I also believe small family farms should be excluded from FARM. FARM is irrelevant for a small operation." Another stated, "Most of the questions [on an evaluation] are geared towards larger farms. There are a lot of questions that make no sense [to smaller farms]."

Other producers indicated unfavorable views with how the FARM program represents smaller operations and concern for the FARM program helping to put smaller operations out of business. One producer said, "Consumers don't like mega-dairies. Regardless of how well they are managed, they are a huge liability for the industry. That needs [to be] addressed by FARM as they won't have public credibility if mega dairies are supported and small herds put out of business." Others added, "It seems like the FARM program wants to put small farmer[s] out of industry," and one producer even claimed, "It seems all you [the program] care about is big farms." Based on these responses, there is an indication that dairy producers who operate smaller herds feel inequalities in the program and do not feel supported by the FARM program, with some even believing that the program may assist in putting them out of business.

Our findings are congruent with recently published literature. A 2016 invited review on animal welfare and herd size highlighted that larger farms were more likely to benefit from and require standard operating procedures and employee training and appeared to be more receptive to science-based recommendations (Robbins et al., 2016), all of which are key components of the FARM Animal Care Program. The program's requirement of protocols and training in different areas of animal care and management could contribute to the perception that smaller dairy farms are at a disadvantage.

Russell and Bewley (2013) found that larger farms (>200 cows) were more likely to use guidance from nutritionists, veterinarians, and other dairy professionals when making management decisions compared with smaller farms. Additionally, according to the National Animal Health Monitoring System, the percentage of US dairy farms that consulted a veterinarian was shown to increase with herd size (USDA NAHMS, 2016). Economies of scale affect how operations can successfully afford compliance and have the ability to spread fixed costs over a larger number of animals, 
thereby reducing production costs per unit of output. In conjunction with perceptions around inequality in standards, implementation of the program standards might feel like more of a burden to smaller farms.

A specific area of concern for small producers that was more programmatic was the way in which animals are sampled during a FARM Animal Care evaluation. One producer said, "I had one sick calf who was skinny. Because of that I had to sign a form saying I had to fix it before the next time I have an evaluation. I do not think this adequately showed how I take care of my animals." Currently, the sample size of required observations is calculated based on the proportion of animals in the herd that are classified into 1 of 4 groups: lactating cows, dry cows, calves, and heifers. Because all animal categories are weighted based on their total proportion to the herd, in small herds with a single animal not performing well and with poor body condition, a continuous improvement plan could be triggered if that animal is randomly selected for observation. This improvement plan would have to be resolved by the due date the evaluator sets, with a maximum date of $3 \mathrm{yr}$. Animal observations are included in the evaluation to determine herd-wide issues that should be addressed, and a single animal could trigger an improvement plan for these observations on smaller farms.

Perceived program inequalities could be addressed by NMPF and the TWG by developing and better communicating the reasons for standards that are facility neutral. Sample size protocol used during an evaluation for animal observations could also be re-evaluated to ensure equality and accuracy while completing animal observations among all sizes of dairy operations during a FARM Animal Care evaluation.

\section{CONCLUSIONS}

The findings of this study demonstrate how some demographic differences among dairy producers affect perceived knowledge, value, and experience with the FARM Animal Care Program. Findings identified areas for improvement that the FARM program could consider for future versions. Many of the survey participants that were not in favor of the program did not perceive FARM as valuable and expressed distrust in the program. Although producers who view the program as valuable and evaluators could be helpful in promoting the program, perceived inequalities could be addressed by inviting greater producer input, developing a strong and consistent communication strategy to be used by cooperatives and processors, and considering sample size protocols in future versions of FARM. This study provides dairy industry professionals with information regarding how dairy producers perceive the FARM
Animal Care Program. Dairy professionals can use this information to target producer groups based on demographics to build knowledge, potentially use evaluators and key dairy producers as spokespeople for the FARM Animal Care Program, and build trust and perceived value through more meaningful producer engagement.

\section{ACKNOWLEDGMENTS}

The authors acknowledge dairy producers who participated in this survey and the dairy cooperatives and processors who assisted with survey distribution. They also acknowledge National Milk Producers Federation for facilitating communication with cooperatives and processors.

\section{REFERENCES}

Cardoso, C. S., M. Hötzel, D. Weary, J. Robbins, and M. von Keyserlingk. 2016. Imagining the ideal dairy farm. J. Dairy Sci. 99:16631671. https://doi.org/10.3168/jds.2015-9925.

Creswell, J. W. 1998. Qualitative Inquiry and Research Design: Choosing Among Five Traditions. Sage Publications, Thousand Oaks, CA.

Creswell, J. W., and V. L. Plano Clark. 2011. Designing and Conducting Mixed Methods Research. 3rd ed. Sage Publications, Thousand Oaks, CA.

Dillman, D. A., J. D. Smyth, and L. M. Christian. 2009. Internet, Mail, and Mixed-Mode Survey: The Tailored Design Method. 4th ed. Wiley, Hoboken, NJ.

Dimitri, C., A. Effland, N. Conklin, and C. Dimitri. 2005. The 20th Century Transformation of US Agriculture and Farm Policy. Vol. 3. USDA Economic Research Service, Washington, DC.

Dwyer, S. C., and J. L. Buckle. 2009. The space between: On being an insider-outsider in qualitative research. Int. J. Qual. Methods 8:54-63. https://doi.org/10.1177/160940690900800105.

Ellis, K., K. Billington, B. McNeil, and D. McKeegan. 2009. Public opinion on UK milk marketing and dairy cow welfare. Anim. Welf. 18:267-282.

FARM Animal Care Program. 2017. FARM Animal Care Program database. Accessed Mar. 30, 2017. https://eval.nationaldairyfarm $. \mathrm{com} /$.

Glesne, C. 2010. Becoming Qualitative Researchers: An Introduction. Pearson, Boston, MA.

Grimshaw, K., R. Miller, M. Palma, and C. Kerth. 2014. Consumer perception of beef, pork, lamb, chicken, and fish. Meat Sci. 96:443444. https://doi.org/10.1016/j.meatsci.2013.07.044.

Heguy, J. M., D. Meyer, and N. Silva-Del-Río. 2016. A survey of silage management practices on California dairies. J. Dairy Sci. 99:16491654. https://doi.org/10.3168/jds.2015-10058.

Kendall, H., L. Lobao, and J. Sharp. 2006. Public concern with animal well-being: Place, social structural location, and individual experience. Rural Sociol. 71:399-428. https://doi.org/10.1526/ 003601106778070617.

R Core Team. 2018. R: A language and environment for statistical computing. R Foundation for Statistical Computing, Vienna, Austria. https://www.R-project.org/.

Robbins, J. A., M. Von Keyserlingk, D. Fraser, and D. Weary. 2016. Invited review: Farm size and animal welfare. J. Anim. Sci. 94:5439-5455. https://doi.org/10.2527/jas.2016-0805.

Russell, R. A., and J. Bewley. 2013. Characterization of Kentucky dairy producer decision-making behavior. J. Dairy Sci. 96:47514758. https://doi.org/10.3168/jds.2012-6538.

Tonsor, G., and C. Wolf. 2011. On mandatory labeling of animal welfare attributes. Food Policy 36:430-437. https://doi.org/10.1016/ j.foodpol.2011.02.001. 
USDA. 2012. US Census of Agriculture: United States summary and state data. Accessed Dec. 14, 2017. https://www.nass.usda.gov/ Publications/AgCensus/2012/Full_Report/Volume_1,_Chapter 1_US/usv1.pdf.

USDA. 2014. 2012 Census of Agriculture highlights: Dairy cattle and milk production. Accessed Nov. 13, 2017. https://www.nass .usda.gov/Publications/Highlights/2014/Dairy_Cattle_and_Milk Production_Highlights.pdf.

USDA. 2017. Animal welfare audits and certification programs. Accessed Jan. 5, 2018. https://www.nal.usda.gov/awic/animal -welfare-audit-and-certification-programs.

USDA ERS (USDA Economic Research Service). 2016. Food consumption and demand. Accessed Mar. 18, 2018. https://www.ers .usda.gov/topics/food-choices-health/food-consumption-demand/.

USDA ERS (USDA Economic Research Service). 2018. Agriculture and its related industries provide 11 percent of U.S. employment. Accessed Jul. 6, 2019. https://www.ers.usda.gov/data-products/ chart-gallery/gallery/chart-detail/?chartId $=58282$.

USDA NAHMS (USDA National Animal Health Monitoring System). 2016. Dairy 2014: Dairy cattle management practices in the United States, 2014. Accessed Jul. 7, 2019. https://www.aphis.usda .gov/animal_health/nahms/dairy/downloads/dairy14/Dairy14 _dr_PartI.pdf.
Voelz, B., C. Payne, L. Hulbert, J. Stevenson, M. Brouk, and L. Mendonca. 2017. Kansas dairy producers' needs survey: Reproductive management on Kansas dairy farms. J. Ext. 55:4.

von Keyserlingk, M. A., J. Rushen, A. de Passillé, and D. Weary. 2009. Invited review: The welfare of dairy cattle - Key concepts and the role of science. J. Dairy Sci. 92:4101-4111. https://doi .org/10.3168/jds.2009-2326.

Wachenheim, C., and R. Rathge. 2000. Societal perceptions of agriculture. Agribusiness and Applied Economics Report 23541. Department of Agribusiness and Applied Economics, North Dakota State University, Fargo.

Wilson, P. 2011. Decomposing variation in dairy profitability: The impact of output, inputs, prices, labour and management. J. Agric. Sci. 149:507-517.

Wolf, C. A. 2003. The economics of dairy production. Vet. Clin. North Am. Food Anim. Pract. 19:271-293.

Wolf, C. A., G. Tonsor, M. Mckendree, D. Thomson, and J. Swanson. 2016. Public and farmer perceptions of dairy cattle welfare in the United States. J. Dairy Sci. 99:5892-5903. https://doi.org/10 .3168/jds.2015-10619. 